\title{
Genetic evaluation of horses based on ranks in competitions
}

\author{
A Tavernier \\ Institut National de la Recherche Agronomique, Station de Génétique Quantitative \\ et Appliquée, Centre de Recherches de Jouy-en-Josas, \\ 78352 Jouy-en-Josas Cedex, France
}

(Received 14 October 1988; accepted 9 January 1991)

\begin{abstract}
Summary - A method is presented for analysing horse performance recorded as a series of ranks obtained in races or competitions. The model is based on the assumption of the existence of an underlying normal variable. Then the rank of an animal is merely the phenotypic expression of the value of this underlying variable relative to that of the other horses entering the same competition. The breeding values of the animals are estimated as the mode of the $a$ posteriori density of the data in a Bayesian context. Calculation of this mode entails solving a non-linear system by iteration. An example involving the results of races of 2-yr-old French trotters in 1986 is given. Practical computing methods are presented and discussed.
\end{abstract}

horse / ranking / order statistics / Bayesian methods

Résumé - Évaluation génétique des chevaux à partir de leurs classements en compétition. Cet article présente une méthode d'analyse de performances enregistrées sous la forme de classements obtenus dans des confrontations restreintes et variables (courses ou concours). Le modèle postule l'existence d'une variable normale sous-jacente. Le classement d'un cheval est alors simplement l'expression phénotypique de la valeur de cette variable sous-jacente relativement à celles des autres animaux participant à la même épreuve. Les valeurs génétiques des animaux sont estimées à partir du mode de la densité a posteriori des données dans un contexte bayésien. Le calcul de ce mode amène à la résolution d'un système non linéaire par itérations. Un exemple d'application est réalisé sur les résultats des courses des chevaux Trotteurs Français de 2 ans en 1986. Des méthodes de calculs pratiques sont proposées et discutées.

cheval / classement / statistiques d'ordre / méthodes bayésiennes

\section{INTRODUCTION}

Choosing a good selection criterion is one of the major problems in genetic evaluation of horses. The breeding objective is the ability to succeed in riding competitions (jumping, dressage, 3-day-event) or in races (trot and gallop). But how should success be measured?

The "career" of a horse is made up of a series of ranks obtained in races or competitions. A "physical" measure of performance is not always available. Such a measure might be racing time for races or number of faults for riding competitions. 
These data are not always collected and, furthermore, they may give a poor indication of the real level of the performance: a racing horse must be fast but it must, above all, adapt to particular conditions prevailing in each event. This may explain the relatively low heritability of time performance of thoroughbreds (Hintz, 1980; Langlois, 1980a). In the case of riding horses, it is difficult to assess the technical level of a jumping event. It depends not only on the height of the obstacles but, to a greater extent, on the difficulties encountered when approaching the obstacles and on the distance between obstacles. None of these variables can be easily quantified.

Therefore, information provided by the ranking of horses in each event deserves attention. Ranking allows horses entering the same event to be compared to the others. However, the level of the event has to be determined too. The most frequently used criterion related to ranking is transformed earnings. Each horse that is "placed" in an event, $i e$, ranked among the first ones, receives a certain amount of money. Prize-money in a race is allocated in an exponential way: for instance, the second horse earns half the amount given to the first, the third half of that given to the second and so on... If the rate of decrease is not $50 \%$, it often equals a fixed percentage, for instance $75 \%$ in horse shows. The earnings of a horse in a race can then be expressed as $G=a x^{(k-1)} D$ with $a$ being the proportion of the total endowment given to the winner (constant), $x$ being the rate of decrease of earning with rank (constant), $k$ the rank of the horse in the race and $D$ the total endowment of the race. The constants $a$ and $x$ must satisfy $\left(a x^{K-1}-x+(1-a)=0\right)$ with $K$ the total number of horses "placed". So, a logarithmic transformation gives $\log (G)=\log (a)+\log (D)+(k-1) \log (x)$. This is a linear function of the rank of the horse. To use it as a function of the ability of the horse, $\log (D)$ should be assumed to be a linear function of the level of the race. The total amount of money given in a race or a competition should depend on the technical difficulty or the level of the competitors. Hence, with adequate competition programmes (Langlois, 1983), the logarithm of earnings of a horse may be a good scale for measuring horse performance and it has been widely used (Langlois, 1980b, 1989; Meinardus and Bruns, 1987; Tavernier, 1988, 1989; Arnason et al, 1989; Klemetsdal, 1989; Minkema, 1989). However, this criterion strongly depends on the way money is distributed. The choice of the amount of money given in jumping competitions does not follow strict technical rules in France and does not directly depend on the scale of technical difficulties but on the choice of the organizing committee. Therefore, it appears that ranks should be taken into account without reference to earnings.

The purpose of this article is to present a method for estimating the breeding value of an animal using a series of ranks obtained in events where it competed against a sample of the population. In order to interpret these data, the notion of underlying variable will be used as in Gianola and Foulley (1983) for estimation of breeding value with categorical data, and in Henery (1981) for constructing the likelihood of outcomes of a race. The horse's "real" performance, which cannot be measured, is viewed as a normal variable; this is a reasonable assumption for traits with polygenic determination. Only the location or ranking of this performance relative to those of the other horses entering the same event is observed. Although this model is applied to horses, it can be extended to any situation where a rank 
is recorded instead of a performance. Practical computational aspects as well as an application to trotters are presented.

\section{METHOD}

\section{Data}

The data $(\mathbf{Y})$ consist of the ranks of all the animals in all the events. The total number of observations is therefore equal to the sum of the number of animals per event. It is assumed that the ranks are related to an underlying unobserved continuous variable. The rank depends on the realized value of this underlying unobserved variable ("real" animal performance) relative to that of the other animals entering the same event. The genetic model is the same as for usual traits with polygenic determinism. The underlying performance $y_{i j k}$ follows a normal distribution with residual standard deviation $\sigma_{e}$ and expected value $\mu_{i j}$. The model is:

$$
y_{i j k}=\mu_{i j}+e_{i j k} \quad \text { with : } \mu_{i j}=b_{i}+u_{j}+p_{j}
$$

where:

$-y_{i j k}=$ "real" performance of horse $j$ under environmental conditions $i$ in the $k$ th race of $j$;

$-b_{i}=$ environmental effect $i$ (eg age, sex, rider...);

$-u_{j}=$ additive breeding value of horse $j$

$-p_{j}=$ environmental effect common to the different performances of horse $j$, as it may participate in several events;

$-e_{i j k}=$ residual effect in $k$ th race.

The vector of parameters to be estimated is $\boldsymbol{\theta}=\left(\mathbf{b}^{\prime}, \mathbf{u}^{\prime}, \mathbf{p}^{\prime}\right)$ where $\mathbf{b}=\left\{b_{i}\right\}$, $\mathbf{u}=\left\{u_{j}\right\}$ and $\mathbf{p}=\left\{p_{j}\right\}$. Inference is based on Bayes theorem. Since the marginal density of $\mathbf{Y}$ does not vary with $\boldsymbol{\theta}$ :

$$
f(\boldsymbol{\Theta} / \mathbf{Y}) \propto g(\mathbf{Y} / \boldsymbol{\Theta}) p(\boldsymbol{\Theta})
$$

where $p(\boldsymbol{\Theta})$ is the prior density of $\boldsymbol{\Theta}, g(\mathbf{Y} / \boldsymbol{\theta})$ is the likelihood function and $f(\boldsymbol{\theta} / \mathbf{Y})$ is the posterior density of the parameters.

\section{Prior density}

The vectors $\mathbf{b}, \mathbf{u}, \mathbf{p}$ and $\mathbf{e}$ are assumed to be mutually independent and to follow the normal distributions: $N(\boldsymbol{\beta}, \mathbf{V}), N(\mathbf{O}, \mathbf{G}), N(\mathbf{O}, \mathbf{H}), N(\mathbf{O}, \mathbf{R})$, respectively. Prior information about $\mathbf{b}$ is assumed to be vague, which implies that the diagonals of $\mathbf{V}$ tend to $+\infty$. Then, the prior density of $\mathbf{b}$ is uniform and the posterior density of $\boldsymbol{\Theta}$ does not depend on $\boldsymbol{\beta} \cdot \mathbf{G}=\mathbf{A} \sigma_{u}^{2}$ where $\mathbf{A}$ is the relationship matrix and $\sigma_{u}^{2}$ is the additive genetic variance. $\mathbf{H}$ is a diagonal matrix with diagonal elements equal to the variance of $\mathbf{p}\left(\sigma_{p}^{2}\right)$. The variances $\sigma_{u}^{2}$ and $\sigma_{p}^{2}$ are assumed to be known, $\sigma_{e}^{2}$ is chosen to be equal to 1 , and $\mathbf{R}$ is an identity matrix. Then:

$$
p(\boldsymbol{\Theta}) \propto \exp \left(-1 / 2 \mathbf{u}^{\prime} \mathbf{G}^{-1} \mathbf{u}\right) \exp \left(-1 / 2 \mathbf{p}^{\prime} \mathbf{H}^{-1} \mathbf{p}\right)
$$




\section{Likelihood function}

Given $\mu_{i}$, the performances $y_{i j k}$ are conditionally independent. Let $y_{(1)}, y_{(2)}, \ldots$, $y_{(n)}$ be the ordered underlying performances of the $n$ horses which competed in an event (for notation, see for example David, 1981, p 4). Then, the likelihood of obtaining the observed ranking in that event can be written as (Henery, 1981; Dansie, 1986):

$$
\begin{gathered}
P_{k}=\operatorname{Prob}\left(y_{(1)}>y_{(2)}>\ldots>y_{(n-1)}>y_{(n)}\right) \\
P_{k}=\int_{-\infty}^{+\infty} \int_{y_{(n)}}^{+\infty} \cdots \int_{y_{(i+1)}}^{+\infty} \int_{y_{(2)}}^{+\infty} \prod_{t=1}^{n} \varphi\left(y_{(t)}-\mu_{(t)}\right) \mathrm{d} y_{(t)}
\end{gathered}
$$

where:

$-\varphi$ is the standard normal density.

$-\mu_{(t)}$ is the location parameter of the horse ranked " $t$ " in that event.

This probability can be interpreted in the following way: the performance of the last animal may vary between $-\infty$ and $+\infty$, the performance of the next to last varies from that of the last to $+\infty$ and so on. Thus, the performance of a horse varies from that of the horse ranked just behind it to $+\infty$, hence leading to the bounds of each integral in $P_{k}$. Each integration variable $(t)$ follows a normal distribution with mean $\mu_{(t)}$ and standard deviation $\sigma_{e}=1$. Given $\mu_{(t)}$, these distributions are independent for all animals in the same competition.

This probability may be expressed in terms of a multivariate normal integral with thresholds independent of integration variables (Godwin, 1949; David, 1981):

$$
\begin{gathered}
P_{k}=\operatorname{Prob}\left(y_{(1)}-y_{(2)}>0, \ldots y_{(t)}-y_{(t+1)}>0, \ldots y_{(n-1)}-y_{(n)}>0\right) \\
\quad \text { or }: P_{k}=\operatorname{Prob}\left(x_{1}>0, \ldots x_{t}>0, \ldots x_{n-1}>0\right)
\end{gathered}
$$

where the distribution of $\left(x_{1}, \ldots, x_{t}, \ldots, x_{n-1}\right)$ is normal with mean $\left(\mu_{(1)}\right.$ $\left.\mu_{(2)}, \ldots, \mu_{(t)}-\mu_{(t+1)}, \ldots, \mu_{(n-1)}-\mu_{(n)}\right)$ and variance $\mathbf{V}=\left\{v_{m l}\right\}$ with $v_{m m}=2$, $v_{m, m-1}=v_{m, m+1}=-1$ and all other $v_{m l}=0$. Then:

$$
\begin{aligned}
P_{k}=\int_{\mu_{(n)}-\mu_{(n-1)}}^{+\infty} \cdots \int_{\mu_{(t+1)}-\mu_{(t)}}^{+\infty} \cdots & \int_{\mu_{(2)}-\mu_{(1)}}^{+\infty} \\
& (2 \pi)^{-(n-1) / 2}(\operatorname{det}(\mathbf{V}))^{-1 / 2} \exp \left(-1 / 2 \mathbf{x}^{\prime} \mathbf{V}^{-1} \mathbf{x}\right) d \mathbf{x}
\end{aligned}
$$

Results of races are likely to be correlated. However, if the model is appropriate, this correlation would depend only on genetic or environmental effects ie given the $\mu_{i j}$ 's, the races are independent. The likelihood function is equal to the product of the probabilities of each event:

$$
g(\mathbf{Y} / \boldsymbol{\theta})=\prod_{k=1}^{m} P_{k}
$$

where $m$ is the total number of races. 


\section{Estimation of parameters}

The posterior density of the parameters is:

$$
f(\boldsymbol{\theta} / \mathbf{Y}, \mathbf{G}, \mathbf{H}) \propto\left(\prod_{k=1}^{m} P_{k}\right) \exp \left(-1 / 2 \mathbf{u}^{\prime} \mathbf{G}^{-1} \mathbf{u}\right) \exp \left(-1 / 2 \mathbf{p}^{\prime} \mathbf{H}^{-1} \mathbf{p}\right)
$$

The best selection criterion is known to be the mean of the posterior distribution (Fernando and Gianola, 1984; Goffinet and Elsen, 1984). As expressing it analytically is not possible for the model used here, we will take as estimator of $\boldsymbol{\theta}$ the mode of the posterior distribution, which can be viewed as an approximation to the optimum selection criterion. Finding this mode is computationaly equivalent to the maximisation of a joint probability mass density function as calculated by Harville and Mee (1984) for categorical data (Foulley, 1987). It is more convenient to use the logarithm of the posterior density:

$L(\boldsymbol{\Theta})=\log (f(\boldsymbol{\Theta} / \mathbf{Y}, \mathbf{G}, \mathbf{H}))=\sum_{k=1}^{m} \log \left(P_{k}\right)-1 / 2 \mathbf{u}^{\prime} \mathbf{G}^{-1} \mathbf{u}-1 / 2 \mathbf{p}^{\prime} \mathbf{H}^{-1} \mathbf{p}+$ constant where $m$ is the number of events.

The system which satisfies the first-order condition is not linear and must be solved iteratively, for example using a Newton-Raphson type algorithm. This algorithm iterates with:

$$
-\left[\frac{\delta^{2} L(\boldsymbol{\Theta})}{\delta \boldsymbol{\Theta} \delta \boldsymbol{\Theta}^{\prime}}\right]_{\boldsymbol{\Theta}=\widehat{\boldsymbol{\Theta}}^{[q-1]}} \Delta^{[q]}=\left[\frac{\delta L(\boldsymbol{\Theta})}{\delta \boldsymbol{\Theta}}\right]_{\boldsymbol{\Theta}=\widehat{\boldsymbol{\Theta}}^{[q-1]}}
$$

where $\widehat{\boldsymbol{\Theta}}^{[q]}$ is the solution for $\boldsymbol{\Theta}$ at the $q$ th round of iteration and $\Delta^{[q]}=\widehat{\boldsymbol{\Theta}}^{[q]}-\widehat{\boldsymbol{\Theta}}^{[q-1]}$. Iterations are stopped when a convergence criterion, a function of $\Delta$, is less than an arbitrarily small number.

The first and second derivatives of $L(\boldsymbol{\theta})$ with respect to $\mathbf{b}, \mathbf{u}, \mathbf{p}$ are reported in Appendix 1.

The system can be written in the following way:

$$
\left[\begin{array}{ccc}
\mathbf{A} & \mathbf{B}^{\prime} & \mathbf{B}^{\prime} \\
\mathbf{B} & \mathbf{C}+\mathbf{G}^{-1} & \mathbf{D}^{\prime} \\
\mathbf{B} & \mathbf{D} & \mathbf{C}+\mathbf{H}^{-1}
\end{array}\right]_{[q-1]}\left[\begin{array}{c}
\widehat{\mathbf{b}} \\
\widehat{\mathbf{u}} \\
\widehat{\mathbf{p}}
\end{array}\right]_{[q]}=\left[\begin{array}{l}
\mathbf{w} \\
\mathbf{z} \\
\mathbf{z}
\end{array}\right]_{[q-1]}
$$

$$
+\left[\begin{array}{lll}
\mathbf{A} & \mathbf{B}^{\prime} & \mathbf{B}^{\prime} \\
\mathbf{B} & \mathbf{C} & \mathbf{D}^{\prime} \\
\mathbf{B} & \mathbf{D} & \mathbf{C}
\end{array}\right]_{[q-1]}\left[\begin{array}{l}
\widehat{\mathbf{b}} \\
\widehat{\mathbf{u}} \\
\hat{\mathbf{p}}
\end{array}\right]_{[q-1]}
$$

where $\mathbf{A}, \mathbf{B}, \mathbf{C}, \mathbf{D}$ are sub-matrices of minus the second derivatives of $\sum_{k=1}^{m} \log \left(P_{k}\right)$ with respect to $\boldsymbol{\theta}$ and $\mathbf{w}, \mathbf{z}$ are the vectors of first derivatives of $\sum_{k=1}^{m} \log \left(P_{k}\right)$ with respect to $\boldsymbol{\Theta}$, excluding variance matrices. 
The numerical solution of system (I) raises the problem of the calculation of the corresponding integrals. Multivariate normal integrals may be calculated with numerical methods such as 'that of Dutt (1973), described and programmed by Ducrocq and Colleau (1986). A second method consists of using a Taylor's series expansion about zero which seems to give good results (Henery, 1981; Dansie, 1986; Pettitt, 1982). This requires that animals participating in a given event have relatively close means $\mu_{i j}$, which is a reasonable assumption in the present context of horse competitions. This expansion involves moments of normal order statistics, as explained in Appendix 2.

\section{Example}

In order to illustrate these computations, a simple example was constructed. This example involves 5 unrelated horses. There are no fixed effects, hence $\mu=(\mathbf{u}+\mathbf{p})$ is estimated. The variance-covariance matrix of $\mu$ is diagonal with each term being 9/11. Two races with 4 runners are considered. The first gave the following ranking: No 1 , No 2, No 3, No 4 and the second: No 3, No 2, No 5, No 4. The starting value for all $\mu$ 's was 0 . The system to be solved at the first iteration of the Newton-Raphson algorithms as well as the corresponding solution are the following:

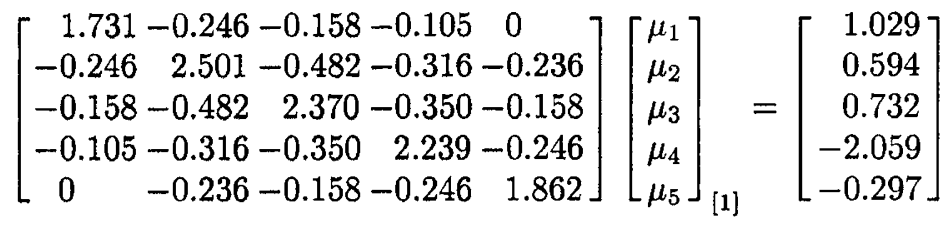

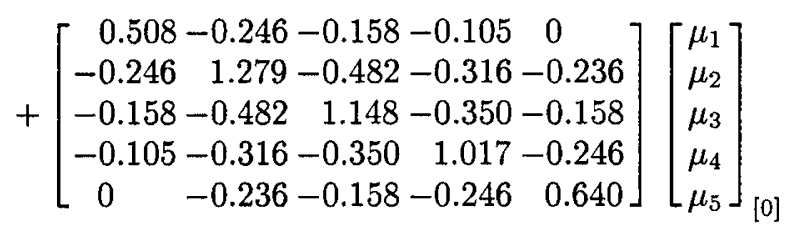

solution: $\left[\begin{array}{lllll}\mu_{1} & \mu_{2} & \mu_{3} & \mu_{4} & \mu_{5}\end{array}\right]=\left[\begin{array}{lllll}0.598 & 0.217 & 0.253 & -0.846 & -0.222\end{array}\right]$

The algorithm converged at the 5th iteration: $\left(\Delta^{\prime} \Delta\right)^{0.5}=6 \times 10^{-17}$. The corresponding values as well as the solutions and the coefficient of determination $(C D)$ with $C D=\left(1-c_{i i} / \sigma_{u}^{2}\right)$ where $c_{i i}$ is the diagonal element of the inverse of the matrix of second derivatives of the logarithm of posterior density are:

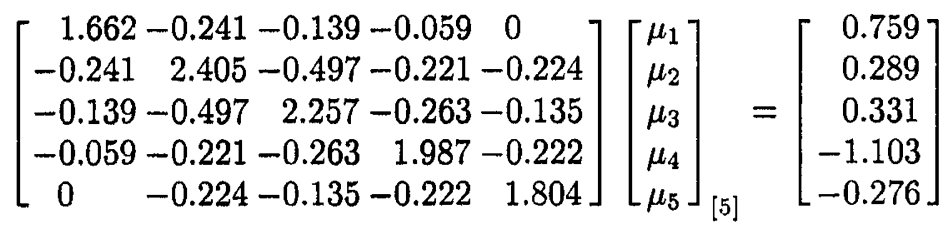




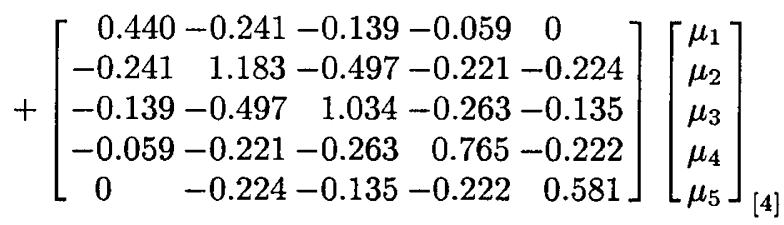

solution: $\left[\begin{array}{lllll}\mu_{1} & \mu_{2} & \mu_{3} & \mu_{4} & \mu_{5}\end{array}\right]=\left[\begin{array}{lllll}0.621 & 0.237 & 0.271 & -0.902 & -0.226\end{array}\right]$ accuracy: [ $\left.\begin{array}{lllll}0.242 & 0.434 & 0.404 & 0.348 & 0.293\end{array}\right]$

It should be noted that the value of the first derivative for a horse in a given race is equal to the expectation of the normal order statistic (normal score) corresponding to its rank. Similarly, second derivatives for a given race are functions of the variance of, and covariances between, normal order statistics. This is the logical consequence of the choice of 0 for $\mu$ as starting value: all distributions of performances are the same with a mean of 0 and all integrals correspond to expectations of normal order statistics. The accumulated values for all races are the sum of these.

At convergence, these values have changed and the final solution differs from the estimates obtained from the expectation of normal order statistics. The interpretation of a rank depends not only on the number of competitors, which is taken into account through the normal order statistics, but also on the level of the competition. At convergence, the first derivative of the $\log$ of a posteriori density is set to 0 . So, estimates of horses are equal to the first derivatives of the log of likelihood function divided by the variance term. These derivatives are different for the same rank in different races. They depend on the level of the race estimated a posteriori by the estimates of the horses participating this particular race, taking into account all races. In the example, for the winners of the 2 races, the first derivatives of the likelihood function were much lower than the expected values of order statistics. This is because the competitors of these races have much lower estimates than the winners: $0.237,0.271,-0.902$ for horses No 2 , No 3 and No 4 against 0.621 for horse No 1 winner of the first race and $0.237,0.226,-0.902$ for horses No 2 , No 5 and No 4 against 0.271 for horse No 3 winner of the second race. Therefore, the first race for No 1 and the second race for No 3 was easier than if they had competed against 3 horses of equal ability to themselves, ie with the same $\mu_{i}$, as implied with the normal order statistics. The values of the first derivatives were 0.7589 and 0.8475 , respectively, compared to 1.0294 for the expectation of the normal order statistics of the first out of 4 . In the same way, in the first race, horse No $3(0.27)$ was beaten by a horse of lesser ability (No $2(0.24)$ ), and, therefore was more penalized than if it had been defeated by a horse of equal ability. The first derivative was -0.5165 , compared to -0.2970 for the expectation of the normal order statistics of the third out of 4 .

\section{APPLICATION}

\section{Data}

This method was used to analyse performances of 2-yr-old French Trotters racing in 1986. These horses entered a series of races reserved to their age class and all 
horses in these races were recorded in the file. Ten races (38 horses) were discarded because they involved only horses that did not compete more than once, and which, therefore, were totally disconnected from the rest of the file. We had to limit the analysis to "placed" horses in each race, ie, horses ranked among the best 4 or 5, because the ranking of other participants were not available. This does not prevent us from testing and comparing our method to usual earning criteria assuming that these races involved only 4 or 5 horses. Indeed, this is neccessary for a fair comparison since earnings also involve only "placed" horses. With our approach, "non placed" horses could, of course, be treated as the others provided that they are filed.

The data set was made up of 251 races (211 with 4 horses ranked and 40 with 5 horses ranked), involving 490 different horses. The total number of performances was 1044 places, ie 2.1 per horse on average, with a maximum of 9 and a minimum of 1 . A horse competed against 3.3 horses on average. The model used was:

$$
y_{j k}=\mu_{j}+e_{j k} \quad \text { with }: \mu_{j}=u_{j}+p_{j}
$$

where:

$-y_{j k}=$ "real" performance of horse $j$ in the $k$ th race of $j$;

$-u_{j}=$ additive breeding value of horse $j$;

$-p_{j}=$ environmental effect common to the different performances of horse $j$;

$-e_{j k}=$ residual effect in $k$ th race about "expected" performance $\mu_{j}$.

No fixed effect was considered because particular conditions of each race (distance, type of ground, season...) are the same for all horses in the race and so have no effect on the result and because trainer and driver effects cannot be used on a small data set (only one horse for the majority of trainers or drivers).

The expectations and variance-covariance matrices are:

$$
E\left[\begin{array}{l}
\mathbf{y} \\
\mathbf{u} \\
\mathbf{p}
\end{array}\right]=\left[\begin{array}{l}
0 \\
0 \\
0
\end{array}\right] \quad \mathbf{V}\left[\begin{array}{l}
\mathbf{u} \\
\mathbf{p} \\
\mathbf{e}
\end{array}\right]=\left[\begin{array}{ccc}
\mathbf{I} \sigma_{u}^{2} & 0 & 0 \\
0 & \mathbf{I} \sigma_{p}^{2} & 0 \\
0 & 0 & \mathbf{I} \sigma_{e}^{2}
\end{array}\right]
$$

where $h^{2}=\sigma_{u}^{2} / \sigma_{y}^{2}$ is the heritability and $r=\left(\sigma_{u}^{2}+\sigma_{p}^{2}\right) / \sigma_{y}^{2}$ is the repeatability of the trait. Values of $h^{2}=0.25$ and $r=0.45$ were chosen as they correspond to usual estimates of these parameters obtained from competitions.

\section{RESULTS}

The elements of system (I) were recalculated at each Newton-Raphson iteration with Dutt's (1973) method for integrals. Convergence was reached after 5 iterations (with $\left(\Delta^{\prime} \Delta\right)^{0.5} / 490=2 \times 10^{-15}$ ). The accuracies of these solutions were measured by coefficient of determination $(C D)$. If $c_{i i}$ is a diagonal element of the matrix of second derivatives, $C D=\left(1-c_{i i} / \sigma_{u}^{2}\right)$.

Breeding value estimates had a mean of 0 , a standard deviation of 0.30 , with a maximum of 0.94 and a minimum of -0.82 . The mean accuracy was 0.23 , with a standard deviation of 0.08 , a maximum of 0.43 and a minimum of 0.12 .

These values were compared to criteria usually employed in trotters (Thery, 1981; Langlois, 1984). The correlations with yearly earning criteria were high: 
0.73 with $\log$ (yearly earning), 0.88 with $\log$ (yearly earning per "place"), 0.79 with $\log$ (yearly earning per start). The correlation with a selection index using as performance the mean of the logarithm of earnings in each race (with parameter values $h^{2}=0.25$ and $r=0.45$ ) was 0.94 . Correlations with criteria related to racing time were lower, as were correlations between earnings and racing time. The correlation was -0.43 between our estimate and the best time per kilometer and -0.47 between our criterion and a selection index using as performance the average racing time (with parameter values $h^{2}=0.25$ and $r=0.45$ ). These figures also suggest that the best racing time is not a good measure of success in a race for 2-yr-old horses.

This application suggests some peculiarities of our method. The first one relates to the spread of accuracy values. These depend not only on the number of "places" but also on the "place" of the horse in the race. Accuracies ranged from 0.25 to 0.33 and from 0.20 to 0.28 for horses having 3 and 2 "places", respectively. The minimal accuracy corresponding to a single "place" $(0.12)$ was smaller than the heritability $(0.25)$. This is the result of the loss of information because ranks are used instead of continuous performances. The average "loss" of accuracy ranged from 0.10 points for horses ranked once to 0.05 for those ranked more than 7 times.

The second point of interest is the relative importance of the number of horses per event and the level of the horses participating in the event. At convergence, the first derivative of the logarithm of posterior density is equal to 0 , so estimates are equal to the part of the first derivative without variance terms divided by these variance terms (see Appendix I). When all horses participating in an event are of the same level (ie, have the same real racing ability) this derivative is equal to expectations of normal statistics. These expectations depend only on the number of animals per event. In our method the first derivative also depends on the real racing abilities of the competitors. So the same rank in different events does not give the same derivative. Figure 1 shows the distribution of the derivatives in all the races with 5 horses "placed" for the different ranks. For a given rank, these derivatives are different in each race and so, being first in a race sometimes gives a lower estimate than being second in a race of a higher level.

Our method can be used as a tool to improve the correspondence between the level of the race and the prize money to be distributed. The average competitive "level" of the race can be approximated as the mean of the estimates of real producing ability $\left(\mu_{j}\right)$ of each horse. In practice, the correlation between such a measure and the logarithm of total endowment of the race was 0.30 for races with 4 horses "place", and 0.65 for races with 5 "placed". Races with 5 horses "placed" have the greatest prize-money, and endowment seemed to be a good indicator of the value of participating horses. It is also possible to calculate a posteriori the probabilities of obtaining the observed ranking in each race - or even of fictitious races - using the estimates for each horse. These probabilities were directly calculated from the formula for $P_{k}$ and do not take into account the accuracy of the estimates. The average probability of obtaining the observed ranks was $11 \%$ and $3 \%$ in races with 4 and 5 horses, respectively. If all horses had the same real producing ability, this probability would be $4 \%$ in races with 4 horses (24 possibilities) and $0.8 \%$ in races with 5 horses (120 possibilities). 


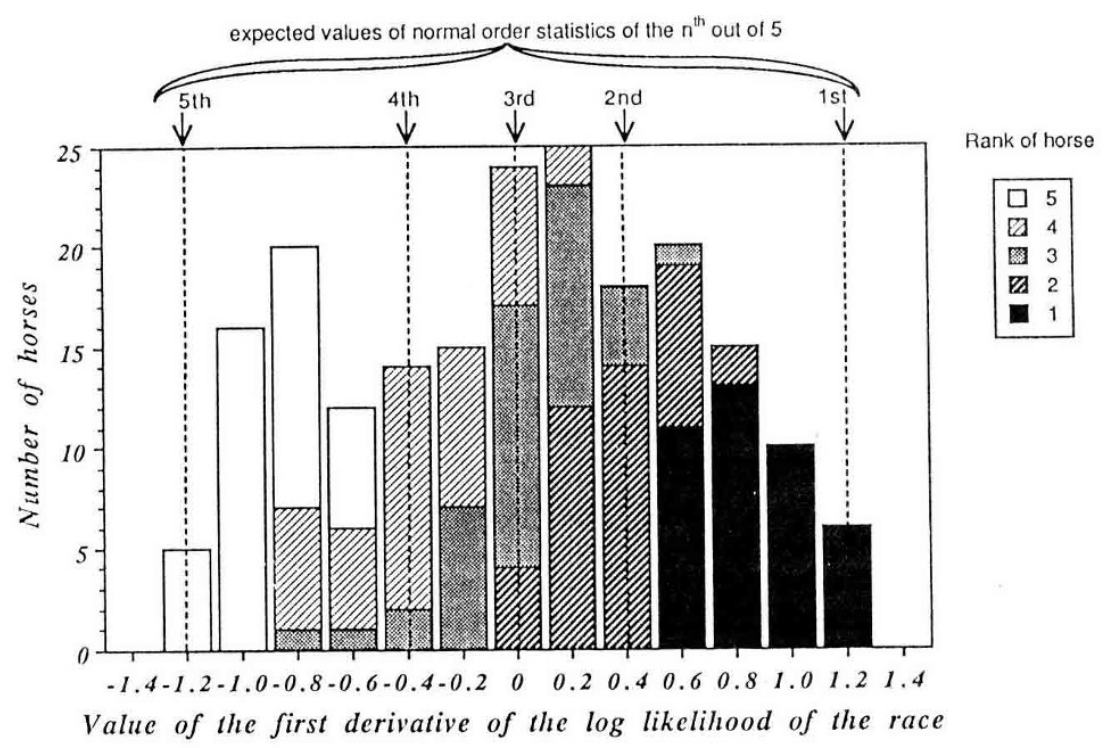

Fig 1. Importance of the rank and the level of the competition in races with 5 horses ranked: distribution of the first derivative at convergence.

\section{DISCUSSION}

In the light of the results obtained with 2-yr-old trotters, the proposed method seemed satisfactory: the estimated values are consistent with other criteria.

In practice, solving a much larger system of equations presents difficulties. Two numerical problems arise, namely the calculation of the integrals $P_{k}$ and their derivatives and the dimensions of the whole system. Two methods for computing the necessary integrals have been suggested, the first being a numerical calculation of multivariate normal integrals and the second an approximation by Taylor's series. Beyond certain dimensions, it takes a very long time to compute multiple integrals of the normal distribution. For each iteration of Newton-Raphson and for each race of $n$ horses, it is necessary to calculate one integral of order $(n-1), n$ integrals of order $(n-2)$ and $[n(n+1) / 2]$ integrals of order $(n-3)$. Therefore, the time needed to accomplish this becomes prohibitive for a number of horses per race $>5$ or 6 . On the other hand, our purpose is to be able to apply this technique to all types of horse competitions (for example show junping) that sometimes involve more than 100 participants. Then, it is necessary to turn to approximations like those proposed by Henery (1981) using Taylor's series. The accuracy of these approximations is difficult to test. In particular, approximate formulae for the moments of order statistics superior to 2 (Pearson and Hartley, 1972; David and Johnson, 1954) need to be tested and compared to integral calculations of high order. Such an approximation reduces calculation times considerably. The moments of order statistics not given in tables can be calculated once and for all. Then, each derivative only consists of a linear combination of the producing abilities of the horses of the race. 
The overall dimension of the system constitutes a second problem. Using an animal model with repeated records, this dimension is equal to the number of horses to be evaluated plus the number of performing horses and fixed effects. At the present time, in France, $\approx 100000$ horses are evaluated in jumping with an animal model (BLUP method) based on yearly earnings and 70000 are evaluated in trotting-races (Tavernier, 1989l, 1990). For each Newton-Raphson iteration of the proposed method, an iterative solution such as Gauss-Seidel will be needed.

This method has been developed to include all horses in every race including "non-placed" horses. However, they will have to be treated in a slightly different manner: the purpose is to consider the horses "placed" as better than the "nonplaced", but detailed ranking of "non-placed" horses is of little interest. The competitor which no longer has a chance of finishing "placed" is not going to try to improve its rank and, therefore, its rank relative to the other "non-placed" horses does not accurately reflect its real ability. Therefore the "non-placed" should be treated as having a performance below that of the last "placed". Then, the likelihood of the outcome of a race can be written as:

$$
P=\int_{-\infty}^{y_{(n)}} \cdots \int_{-\infty}^{y_{(n)}} \int_{-\infty}^{+\infty} \int_{y_{(n)}}^{+\infty} \cdots \int_{y_{(i+1)}}^{+\infty} \int_{y_{(2)}}^{+\infty} \prod_{j=1}^{n^{\prime}} \varphi\left(y_{(j)}-\mu_{(j)}\right) \mathrm{d} y_{(j)}
$$

where there are $n^{\prime}$ horses in the race and $n$ horses "placed". This integral can be used in this form or equivalently as the sum of all the integrals over all possible rank combinations between "non-placed" horses, which allows a simplified application of the calculation by Taylor's approximation.

Another difficulty is the estimation of the genetic parameters. The estimation of variance components could probably be made using a marginal maximum likelihood approach which requires the inversion of the matrix of second derivatives, as discussed by Gianola et al (1986) and applied by Foulley et al (1987a, b). In practice, this method can be applied only on a reduced data file or with a "sire" model.

The heritability of a single performance is lower than that of yearly earning criteria. Yearly criteria are compound functions of the number of events and of success in each event. For instance, for single performance, Meinardus and Bruns (1987) reported $h^{2}=0.18$ and $r=0.48$ for the logarithm of earnings in jumping shows, Klemetsdal (1989) reported $h^{2}=0.18$ and $r=0.65$ for time in trotting-races, Thery (1981) found $h^{2}=0.23$ and $r=0.52$ for the same criterion and $h^{2}=0.07$ and $r=0.13$ for the logarithm of earnings. However, the number of elementary performances during the lifetime of a horse is sufficient to expect good accuracies of estimations. Taking the previous examples and a number of yearly starts equal to 12 (the average number of yearly starts for an adult horse is 12 in trotting-races and 14 in riding competitions), the accuracies of breeding value estimation ranged from 0.27 to 0.41 after one year of performance. With a loss of 0.10 point due to the use of ranks, accuracies of evaluations based on ranks would range from 0.17 to 0.31 , which is reasonable.

This model requires a sufficiently large amount of comparisons between horses to allow a proper classification. The presence of isolated events which do not overlap with others hinders any relative estimation. The method does not avoid 
the necessity of good connections between races, which is the only guarantee of a reliable result.

\section{CONCLUSION}

This article describes a method of evaluation of the breeding value of an animal from its rank relative to those of other competitors in a given event, without using a direct measure of performance. It is interesting that the method suggests a solution based on a conventional genetic model. It can be applied to an "individual animal" model as well as to a "sire" model. It takes into account the level of the competition which is the main factor influencing a rank's value, together with the number of participants in the event. Although use of ranks may seem to lead to a loss of information compared to a physical measure, it is sometimes more reliable. In the case of horse races, ranking is absolutely necessary as a real physical measure is not identifiable. It may also be useful in the case of a distorted scale of measure or when the usual physical measure is nothing but the transcription of a rank.

\section{REFERENCES}

Arnason T, Bendroth M, Phillipsson J, Henriksson K, Darenius A (1989) Genetic evaluation of Swedish trotters. In: State of Breeding Evaluation in Trotters. EAAP Publ No 42, Pudoc, Wageningen, 106-130

Dansie BR (1986) Normal order statistics as permutation probability models. Appl Statist 35, 269-275

David FN, Johnson NL (1954) Statistical treatment of censored data. I. Fundamental formulae. Biometrika 41, 228-240

David HA (1981) Order Statistics. Wiley, NY, 2nd edn, p 360

Ducrocq V, Colleau JJ (1986) Interest in quantitative genetics of Dutt's and Deak's methods for numerical computation of multivariate normal probability integrals. Génét Sél Evol 18, 447-474

Dutt JE (1973) A representation of multivariate probability integrals by integral transforms. Biometrika $60,637-645$

Fernando RL, Gianola D (1984) Optimal properties of the conditional mean as a selection criterion. J Anim Sci 59 (suppl), 177 (abstr)

Foulley JL (1987) Méthodes d'Évaluation des Reproducteurs pour des Caractères Discrets à Déterminisme Polygénique en Sélection Animale. Thèse d'état, Université de Paris-Sud, Centre d'Orsay, pp 320

Foulley JL, Gianola D, Planchenault D (1987a) Sire evaluation with uncertain paternity. Génét Sél Evol 19, 83-102

Foulley JL, Im S, Gianola D, Hoschele I (1987b) Empirical Bayes estimation of parameters for $n$ polygenic binary traits. Génét Sél Evol 19, 197-204

Gianola D, Foulley JL (1983) Sire evaluation for ordered categorical data with a threshold model. Génét Sél Evol 15, 201-224

Gianola D, Foulley JL, Fernando RL (1986) Prediction of breeding values when variances are not known. Génét Sél Evol 18, 485-498 
Godwin HJ (1949) Some low moments of order statistics. Ann Math Statist 20, 279-285

Goffinet B, Elsen JM (1984) Critère optimal de sélection: quelques résultats généraux. Génét Sél Evol 16, 307-318

Harville DA, Mee RW (1984) A mixed model procedure for analyzing ordered categorical data. Biometrics 40, 393-408

Henery RJ (1981) Permutation probabilities as models for horse races. JR Statist Soc 43, 86-91

Hintz RL (1980) Genetics of performance in the horse. J Anim Sci 51, 582-594

Klemetsdal G (1989) Norwegian trotter breeding and estimation of breeding values. In: State of Breeding Evaluation in Trotters. EAAP Publication No 42, Pudoc, Wageningen, 95-105

Langlois B (1980a) Heritability of racing ability in thoroughbreds. A review. Livest Prod Sci 7, 591-605

Langlois B (1980b) Estimation de la valeur génétique des chevaux de sport d'après les sommes gagnées dans les compétitions équestres françaises. Ann Génét Sél Anim $12,15-31$

Langlois B (1983) Quelques réflexions au sujet de l'utilisation des gains pour apprécier les performances des chevaux trotteurs. 34th Ann Meet EAAP, Madrid, Spain, October 3-6, 1983, Study Commission on Horse Production

Langlois B (1984) Héritabilité et corrélations génétiques des temps records et des gains établis par les Trotteurs Français de 2 à 6 ans. 35th Ann Meet EAAP, The Hague, The Netherlands, August 6-9, 1984, Study Commission on Horse Production Langlois B (1989) Breeding evaluation of French trotters according to their race earnings. I. Present situation. In: State of Breeding Evaluation in Trotters. EAAP. Publication No 42, Pudoc, Wageningen, 27-40

Meinardus H, Bruns E (1987) BLUP procedure in riding horses based on competition results. 38th Ann Meet EAAP, Lisbon, Portugal, September 28-October 1, 1987, Study Commission on Horse Production

Minkema D (1989) Breeding value estimation of trotters in the Netherlands. In: State of Breeding Evaluation in Trotters. EAAP Publication No 42, Pudoc, Wageningen, 82-94.

Pearson ES, Hartley HO (1972) Biometrika Tables for Statisticians. Cambridge University Press, vol 2, 27-35

Pettitt AN (1982) Inference for the linear model using a likelihood based on ranks. JR Statist Soc 44, 234-243

Tavernier A (1988) Advantages of BLUP animal model for breeding value estimation in horses. Livest Prod Sci 20, 149-160

Tavernier A (1989) Breeding evaluation of French trotters according to their race earnings. II. Prospects. In: State of Breeding Evaluation in Trotters. EAAP Publication No 42, Pudoc, Wageningen, 41-54

Tavernier A (1989b) Caractérisation de la population Trotteur Français d'après leur estimation génétique par un BLUP modèle animal. Ann Zootech 38, 145-155

Tavernier A (1990) Caractérisation des chevaux de concours hippique français d'après leur estimation génétique par un BLUP modèle animal. Ann Zootech 39, $27-44$ 
Thery C (1981) Analyse génétique et statistique des performances des Trotteurs Français en courses en 1979 et 1980. Mémoire de Diplôme d'Etudes Approfondies de Génétique Quantitative et Appliquée, Université Paris XI, pp 80

\section{APPENDIX 1}

\section{Calculation of the first and second derivatives of the logarithm of the a posteriori density}

Let $y_{(1)}, y_{(2)}, \ldots, y_{(n)}$ be the ordered underlying performances of the $n$ horses which have participated in race $k$ (see, for example, David, 1981, p 4). Further, let $Q_{(t), k}, R_{(t)(t), k}, R_{(t)(z), k}$ be:

$$
\begin{aligned}
& Q_{(t), k}=\int_{-\infty}^{+\infty} \cdots \int_{y_{(t+1)}}^{+\infty} \cdots \int_{y_{(2)}}^{+\infty} \varphi\left(y_{(n)}-\mu_{(n)}\right) \\
& \cdots\left(y_{(t)}-\mu_{(t)}\right) \varphi\left(y_{(t)}-\mu_{(t)}\right) \cdots \varphi\left(y_{(1)}-\mu_{(1)}\right) \mathrm{d} y_{(n)} \cdots \mathrm{d} y_{(1)} \\
& R_{(t)(t), k}=\int_{-\infty}^{+\infty} \cdots \int_{y_{(t+1)}}^{+\infty} \cdots \int_{y_{(2)}}^{+\infty} \varphi\left(y_{(n)}-\mu_{(n)}\right) \\
& \cdots\left(y_{(t)}-\mu_{(t)}\right)^{2} \varphi\left(y_{(t)}-\mu_{(t)}\right) \cdots \varphi\left(y_{(1)}-\mu_{(1)}\right) \mathrm{d} y_{(n)} \cdots \mathrm{d} y_{(1)} \\
& R_{(t)(z), k}=\int_{-\infty}^{+\infty} \cdots \int_{y_{(z+1)}}^{+\infty} \cdots \int_{y_{(t+1)}}^{+\infty} \cdots \int_{y_{(2)}}^{+\infty} \varphi\left(y_{(n)}-\mu_{(n)}\right) \\
& \cdots\left(y_{(z)}-\mu_{(z)}\right) \varphi\left(y_{(z)}-\mu_{(z)}\right) \\
& \cdots\left(y_{(t)}-\mu_{(t)}\right) \varphi\left(y_{(t)}-\mu_{(t)}\right) \cdots \varphi\left(y_{(1)}-\mu_{(1)}\right) \mathrm{d} y_{(n)} \cdots \mathrm{d} y_{(1)}
\end{aligned}
$$

We have:

$$
\bullet \frac{\delta L(\boldsymbol{\theta})}{\delta u_{j}}=\sum_{(k,(t)) \in j} \frac{Q_{(t), k}}{P_{k}}-\left[\mathbf{G}^{-1}\right]_{j} \mathbf{u}
$$

where:

$-(k,(t)) \in j$ indicates the set of events $k$ in which the animal $j$ competed and obtained the rank $t$;

$-\left[\mathbf{G}^{-1}\right]_{j}$ indicates the row corresponding to animal $j$ in inverse of $\mathbf{G}$.

$$
\begin{gathered}
\bullet \frac{\delta L(\boldsymbol{\theta})}{\delta p_{j}}=\sum_{(k,(t)) \in j} \frac{Q_{(t), k}}{P_{k}}-\left[\mathbf{H}^{-1}\right]_{j} \mathbf{p} \\
\bullet \frac{\delta L(\boldsymbol{\Theta})}{\delta b_{i}}=\sum_{k} \sum_{(t) \in i} \frac{Q_{(t), k}}{P_{k}}
\end{gathered}
$$


where:

$-(t) \in i$ indicates the horses ranked at the place $t$ in the event $k$ and with associated fixed effect $i$

$$
\bullet \frac{\delta^{2} L(\boldsymbol{\theta})}{\delta u_{j}^{2}}=\sum_{(k,(t)) \in j}-1+\frac{R_{(t)(t), k}}{P_{k}}-\left(\frac{Q_{(t), k}}{P_{k}}\right)^{2}-\left[\mathbf{G}^{-1}\right]_{j j}
$$

and, if the horses $j$ and $l$ have participated in the same event:

$$
\bullet \frac{\delta^{2} L(\boldsymbol{\theta})}{\delta u_{j} \delta u_{l}}=\sum_{\substack{k \in j, l \\(t) \text { rank of } i \\(z) \text { rank of } h}} \frac{R_{(t)(z), k}}{P_{k}}-\frac{Q_{(t), k} Q_{(z), k}}{\left(P_{k}\right)^{2}}-\left[\mathbf{G}^{-1}\right]_{j l}
$$

The second derivatives with respect to $\mathbf{u}$ and $\mathbf{p}$, or $\mathbf{p}$ and $\mathbf{p}$ are built in the same way. The only value that changes is the covariance which is equal to 0 between $\mathbf{u}$ $\mathbf{p}$ and is equal to $1 / \sigma_{p}^{2}$ on the diagonal of the second derivatives with respect to $\mathbf{p}$ and $\mathbf{p}$.

$$
\cdot \frac{\delta^{2} L(\boldsymbol{\theta})}{\delta b_{i} \delta u_{j}}=\sum_{(k,(t)) \in j}\left[\xi_{i(t)}(-1)+\sum_{(z) \in i} \frac{R_{(t)(z), k}}{P_{k}}-\frac{Q_{(t), k} Q_{(z), k}}{\left(P_{k}\right)^{2}}\right]
$$

where:

- $\xi i(t)=0$ if fixed effect $i$ does not influence the horse ranked $t$

$-\xi i(t)=1$ if fixed effect $i$ influences the horse ranked $t$

$$
\bullet \frac{\delta^{2} L(\boldsymbol{\theta})}{\delta b_{i} \delta b_{h}}=\sum_{k}\left[\sum_{(t) \in i, h}(-1)+\sum_{(t) \in i,(z) \in h} \frac{R_{(t)(z), k}}{P_{k}}-\frac{Q_{(t), k} Q_{(z), k}}{\left(P_{k}\right)^{2}}\right]
$$

\section{APPENDIX 2}

\section{Approximation of first and second derivatives of $10 g$ of the a posteriori density using Taylor's series expansion}

These expansions are drawn from those used by Henery (1981) and Dansie (1986) who approximate the probability $P_{k}$. An example of these decompositions is given for $\left(Q_{(t), K} / P_{k}\right)$ :

$$
\frac{Q_{(t), k}}{P_{k}} \approx e_{t: n}+\left(-1+\sigma_{t t: n}\right) \mu_{(t), k}+\sum_{p=1, p \neq t}^{n} \sigma_{t p: n} \mu_{(p), k}+(1 / 2) \sum_{p=1, z=1}^{n} \rho_{t p z: n} \mu_{(p), k} \mu_{(z), k}
$$

where, for $n$ independent normal distributions:

$-e_{t: n}$ : expectation of the $t$ th order statistic

$-\sigma_{t t: n}$ : variance of the $t$ th order statistic

- $\sigma_{t p: n}:$ covariance between the $t$ th order statistic and the $p$ th order statistic

$-\rho_{t p z: n}:$ moment of order 3 between the $t$ th, $p$ th and the $z$ th order statistics. 